\title{
Activating Natural Killer Cell Receptors, Selectins, and Inhibitory Siglecs Recognize Ebolavirus Glycoprotein
}

\author{
Mostafa Jarahian ${ }^{\text {a }}$ Katharina Marstaller ${ }^{a}$ Nadine Banna ${ }^{a}$ Roshanak Ahani ${ }^{b}$ \\ Mohammad Hossein Etemadzadeh $^{b}$ Lea K. Boller ${ }^{c}$ Kayhan Azadmanesh $^{b}$ \\ Angel Cid-Arregui ${ }^{d}$ Abdolrahman Khezrie Martin R. Berger ${ }^{a}$ Frank Momburg ${ }^{f}$ \\ Carsten Watzl ${ }^{\mathrm{C}}$ \\ aToxicology and Chemotherapy Unit, German Cancer Research Center (DKFZ), Heidelberg, Germany; ${ }^{b}$ Department \\ of Virology, Pasteur Institute of Iran, Tehran, Iran; 'Department of Immunology, Leibniz Research Centre for Working \\ Environment and Human Factors, Technical University Dortmund, Dortmund, Germany; ${ }^{\text {Targeted Tumor Vaccines }}$ \\ Unit, German Cancer Research Center (DKFZ), Heidelberg, Germany; eDepartment of Biotechnology, Inland Norway \\ University of Applied Sciences, Hamar, Norway; ${ }^{\mathrm{f} A n t i g e n ~ P r e s e n t a t i o n ~ a n d ~ T / N K ~ C e l l ~ A c t i v a t i o n ~ U n i t, ~ G e r m a n ~ C a n c e r ~}$ \\ Research Center (DKFZ), Heidelberg, Germany
}

\section{Keywords}

Ebolavirus glycoprotein · Siglecs · Natural cytotoxicity receptors $\cdot$ Selectins $\cdot$ HPV

\begin{abstract}
Expression of the extensively glycosylated Ebolavirus glycoprotein (EBOV-GP) induces physical alterations of surface molecules and plays a crucial role in viral pathogenicity. Here we investigate the interactions of EBOV-GP with host surface molecules using purified EBOV-GP, EBOV-GP-transfected cell lines, and EBOV-GP-pseudotyped lentiviral particles. Subsequently, we wanted to examine which receptors are involved in this recognition by binding studies to cells transfected with the EBOV-GP as well as to recombinant soluble EBOVGP. As the viral components can also bind to inhibitory receptors of immune cells (e.g., Siglecs, TIM-1), they can even suppress the activity of immune effector cells. Our data show that natural killer (NK) cell receptors NKp44 and NKp46, selectins (CD62E/P/L), the host factors DC-SIGNR/DC-SIGN, and inhibitory Siglecs function as receptors for EBOV-GP. Our re-
\end{abstract}

karger@karger.com www.karger.com/jin

Karger"

BOPEN ACCESS
(C) 2021 The Author(s)

Published by S. Karger AG, Basel

This is an Open Access article licensed under the Creative Commons Attribution-NonCommercial-4.0 International License (CC BY-NC) (http://www.karger.com/Services/OpenAccessLicense), applicable to the online version of the article only. Usage and distribution for commercial purposes requires written permission. sults show also moderate to strong avidity of homing receptors (P-, L-, and E-selectin) and DC-SIGNR/DC-SIGN to purified EBOV-GP, to cells transfected with EBOV-GP, as well as to the envelope of a pseudotyped lentiviral vector carrying the EBOV-GP. The concomitant activation and inhibition of the immune system exemplifies the evolutionary antagonism between the immune system and pathogens. Altogether these interactions with activating and inhibitory receptors result in a reduced NK cell-mediated lysis of EBOVGP-expressing cells. Modulation of these interactions may provide new strategies for treating infections caused by this virus.

(c) 2021 The Author(s)

Published by S. Karger AG, Basel

\section{Introduction}

Ebolavirus (EBOV) and Marburg virus are two (2) genera of the Filoviridae family belonging to the most virulent viruses known, which in humans cause a rapidly fatal hemorrhagic fever $[1,2]$. EBOV is able to infect al- 
most every cell type with a rapid rate of viral replication [3]. Treatment is still largely symptomatic, but there are currently 2 licensed Ebola vaccines: The first licensed Ebola vaccine was the rVSV-ZEBOV vaccine made by Merck which was approved by the US FDA in 2019. The heterologous 2-dose Ad26.ZEBOV/MVA-BN-Filo vaccine by Janssen received marketing authorization approval under exceptional circumstances by the European Medicines Agency in 2020. Both of these vaccines have undergone in phase 3/2 trials, respectively (WHO; https:// www.who.int/groups/global-advisory-committee-onvaccine-safety/topics/ebola-virus- vaccines). In addition, a series of monoclonal antibodies have been used successfully alone or in combination [4].

The EBOV genome contains 7 different genes $\left(3^{\prime}\right.$-NPVP35-VP40-GP-VP30-VP24-L-5'), out of which the GP gene forms at least 3 different glycoproteins (GPs) via alternative open reading frames (2-4). The other 6 genes code for structural proteins and the polymerase L of filovirus particles.

These GPs can be modified by various enzymes. After $\mathrm{N}$ - and $\mathrm{O}$-glycosylation, GP0 is cleaved by the enzyme furin to yield the GP1 and GP2 subunits $[5,6]$. GP is structured in a chalice-like shape with a trimer of GP1/ GP2 heterodimers, out of which GP2 is forming the base and GP1 the cup [7]. This GP trimer can be cleaved from the viral surface via the tumor necrosis factor- $\alpha$ converting enzyme [7]. GP1 is mucin-like and contains $\mathrm{N}$-glycosylated as well as $\mathrm{O}$-glycosylated areas, where mutations permanently take place, thus enabling immune escape $[8,9]$, whereas GP2 has only $2 \mathrm{~N}$-glycosylated areas $[10,11]$. GP1 is responsible for receptor binding (including $\alpha$-dystroglycan, heparan sulfate, DC-SIGN, etc.) and GP2 mediates low $\mathrm{pH}$-induced membrane fusion. Both proteins interact with each other to form a stable homotrimer complex on the viral envelope $[12,13]$.

Fuller and colleagues have shown that both Marburg virus-like particles and EBOV-like particles trigger a consistent upregulation of CD69 on the cell surface of polyclonal natural killer (NK) cells from different donors [14]. Upregulation of CD69 on NK cells is closely linked with activation of several signal transduction pathways including survival and induction of cytokine production and cytolysis of targets $[15,16]$. In addition, EBOV infection induces massive NK cell apoptosis, thus avoiding NK function and impairing NK-mediated DC maturation [17-19].

The killer cell immunoglobulin-like receptors (KIRs) as well as Siglecs, and CD94-NKG2A, are involved in the inhibitory signal cascade of NK cells. Most inhibitory receptors recognize specific MHC class I isoforms and thereby ensure tolerance of NK cells against self [20]. NK cell activation is mediated by receptors such as KIR2DS1-5, NKG2D, CD16, or NCRs (natural cytotoxicity receptors NKp46, NKp44, and NKp30). In previous work, we were able to show that ligands for NKp30 and NKp44 can be detected on the surface and in intracellular compartments of different tumor cells [21]. These ligands often contain heparan sulfate linked to proteoglycans [22,23]. Besides recognizing tumor cells, activating NK cell receptors have also been shown to be involved in detecting virus-infected cells by the interaction with various viral surface proteins. As an example, NKp30 and NKp46 present on NK cells play a key role in the immune response against vaccinia virus and mouse poxvirus (ECTV/ectromelia virus), as they bind to hemagglutinin (HA) - a component of the vaccinia virus envelope [24]. It should be noted that NKp30-triggered activation of NK cells is blocked by HA of vaccinia virus, whereas HA stimulates NK cells through NKp46 [24]. Moreover, the pp65 matrix protein of human cytomegalovirus binds NKp30 and inhibits its function [25]. The results indicate that $\mathrm{NKp} 30$ has a different role in NK-cell cytotoxicity $[24,26,27]$. NKp46 recognizes the sigmal protein of reovirus [28]. In addition, the HA proteins of Sendai-, influenza-, and Newcastle disease viruses are able to bind NKp46 and NKp44, and induce NK cell activation [29-32]. NKp44 interacts with envelope glycoproteins from the West Nile and dengue virus E/M proteins [33].

DC-SIGN (CD209) and DC-SIGNR (DC-SIGN-related, CD299, CLEC4M) bind to soluble EBOV-GPs with similar avidity [34], as well as soluble human immunodeficiency virus type-1 (HIV-1) gp120. This interaction is inhibited in an environment with increased $\mathrm{pH}$ [34]. DCSIGN and DC-SIGNR are calcium-dependent C-type lectins, which have high avidity for ICAM3 (CD50) [35]. DC-SIGN binds to weakly polysialylated NCAM-1 [36]. Recently, it was found that TIM-1 (T-cell immunoglobulin and mucin domain 1) is a filovirus receptor [37] and interacts by its phosphatidylserine (Ptd-L-Ser) binding pocket directly with Ptd-L-Ser located on the viral capsid [38-40]. Furthermore, TIM-1 binds the adhesion receptor P-selectin and mediates T-cell trafficking during inflammation and autoimmunity $[41,42]$.

L-selectin is a cell adhesion molecule expressed on most circulating cells, including neutrophils, dendritic cells, monocytes, B cells, NK cells, and T cells. L-selectin is a major regulator of transendothelial migration of leukocytes. E- and P-selectin are expressed on endothelial cells at sites of inflammation and interact with receptors on the surfaces of leukocytes. Also, selectins have been shown to interact with viral proteins. The glycoprotein 
gp120 of HIV-1 binds L-selectin in solution and on the host cell membrane. Upon entry of HIV into $\mathrm{CD} 4^{+} \mathrm{T}$ cells, L-selectin is cleaved at the membrane proximal site by proteolysis, thus facilitating virus release from cells $[43,44]$. Given that fact that many NK cell receptors can interact with viral proteins and that NK cells seem to be involved in EBOV infections, we wanted to investigate the interactions of EBOV-GP with different host cell surface proteins. Here we use purified EBOV-GP, EBOVGP-transfected cells, and EBOV-GP-pseudotyped lentiviral particles to show an interaction with the NK cell receptors NKp44 and NKp46, Siglec-7, the host factors DC-SIGN and DC-SIGNR, P-selectin, and L-selectin. These interactions result in reduced NK cell-mediated killing of EBOV-GP expressing cells.

\section{Materials and Methods}

\section{Cell Lines}

Human embryonic kidney cells HEK-293 (ATCC CRL-3216) and CHO-K1 (ATCC CCL-61) were cultured in RPMI 1640 (Invitrogen, Karlsruhe, Germany) supplemented with $2 \mathrm{~mm}$ glutamine and $10 \%$ fetal calf serum (FCS). Human polyclonal NK cells were isolated by NK cell negative isolation kit (Miltenyi) from peripheral blood mononuclear cells or from healthy donor buffy coats. Between 95 and $99 \%$ of NK cells were CD3 negative and CD56 positive. Cells were grown in Iscove's modified Dulbecco's medium (Invitrogen) with 10\% human serum, penicillin-streptomycin, and $100 \mathrm{IU} / \mathrm{mL}$ IL-2 (NIH Cytokine Repository, Bethesda, MD, USA).

\section{Transfections}

Prof. S. Becker (Institute of Virology, Marburg University, Germany) kindly provided the expression vector pCAGGS-ZEBOVGP for transfection of HEK-293 cells together with empty pcDNA3.1(+) (Invitrogen) to provide for a neomycin resistance gene in trans. Furthermore, we used the expression vector pcDNA6/ V5-His-A/ZEBOV-GP (plasmid 7616.5) for transfection of HEK293 cells and CHO-K1 cells. Empty pcDNA6/V5-His-A was used for vector control transfectants. A total of $2.5 \times 10^{5} \mathrm{HEK}-293$ cells and $\mathrm{CHO}-\mathrm{K} 1$ cells were cultured in 6-well plates and transfected with $4 \mu \mathrm{g}$ of the mentioned plasmids using lipofectamine 2000 (Invitrogen) according to the manufacturer's instructions. Two days later, cells were selected with geneticin $(1 \mathrm{mg} / \mathrm{mL})$ or blasticidin $(10 \mu \mathrm{g} / \mathrm{mL})$ and, after being sorted for high-level GP expression, maintained in $0.5 \mathrm{mg} / \mathrm{mL}$ geneticin or $5 \mu \mathrm{g} / \mathrm{mL}$ blasticidin. GP expression was detected via mouse monoclonal anti-ZEBOV GP antibody 3B11 [45] (kindly provided by Prof. Stephan Becker, Institute of Virology, Marburg) and human monoclonal anti-ZEBOV GP antibody KZ52 [46] (dilution 1:200). KZ52 was purchased from IBT BioServices (Rockville, MD, USA).

Chromium Release Assay

EBOV-GP-transfected HEK-293 cells, which were used as target cells $\left(0.5 \times 10^{6}\right)$ in $100 \mu \mathrm{L}$ of assay medium (Iscove's modified Dulbecco's medium with $10 \%$ FCS and $1 \%$ penicillin-streptomy- cin), were labeled with $100 \mu \mathrm{Ci}(3.7 \mathrm{MBq})$ of ${ }^{51} \mathrm{Cr}$ (Hartmann \& Braun, Frankfurt, Germany) for $1 \mathrm{~h}$ at $37^{\circ} \mathrm{C}$. Cells were washed twice and resuspended in assay medium at $5 \times 10^{4}$ cells $/ \mathrm{mL}$. Isolated NK cells were seeded in 96-well round-bottom plates (Nunc) at a density of $1.5-2 \times 10^{6} / \mathrm{mL}$ with irradiated feeder cells (K562mbIL15-41BBL) in medium with $100 \mathrm{ng} / \mathrm{mL}$ IL-21 (Miltenyi Biotec) and $200 \mathrm{U} / \mathrm{mL}$ IL-2 (National Institutes of Health Cytokine Repository). After the first week, NK cells were restimulated with fresh feeder cells. In the next weeks, NK cells were split to a density of $1.5-2 \times 10^{6} / \mathrm{mL}$ in the presence of $100 \mathrm{U} / \mathrm{mL}$ IL-2. On day $14,2.5 \mathrm{ng} / \mathrm{mL}$ recombinant IL-15 (PAN Biotech) was added. After 3 weeks, NK cells were used for ${ }^{51} \mathrm{Chromium}$-release assay. These effector cells were resuspended in assay medium and mixed at different effector-to-target cell ratios with 5,000 labeled target cells/ well in a 96-well F-bottom plate. Maximum release was determined by the incubation of target cells in 1\% Triton X-100 solution. Spontaneous ${ }^{51} \mathrm{Cr}$ release was measured by incubating target cells in the absence of effector cells. All samples were prepared in triplicate. Plates were incubated for $4 \mathrm{~h}$ at $37^{\circ} \mathrm{C}$. Supernatant was harvested, and ${ }^{51} \mathrm{Cr}$ release was measured in a $\gamma$-counter. The percentage of cytotoxicity was calculated according to the following formula: ([chromium release for condition of interest - chromium release in spontaneous wells]/[max chromium release - chromium release in spontaneous wells] $) \times 100$. Representative examples from 3 similar experiments are shown.

\section{Enzyme-Linked Immunosorbent Assay}

For the direct detection of EBOV-GP via enzyme-linked immunosorbent assay (ELISA) plates, we obtained the human EBOV Zaire glycoprotein from Advanced Biomart (San Gabriel, CA, USA) and the recombinant human anti-EBOV GP antibody [KZ52] from Absolute Antibody (Oxford, GB). EBOV-GP was expressed with a polyhistidine-tag at the C-terminus and consists of 629 amino acids, predicting a molecular mass of $69 \mathrm{kDa}$. This antibody detects purified EBOV-GP coated on ELISA plates and HEK-293 ${ }^{\text {EBOV-GP }}$ cells by IF. MicroTest III ELISA plates (BD Biosciences, Heidelberg, Germany) were coated overnight with EBOV-GP in $0.05 \mathrm{M} \mathrm{NaHCO}_{3}-\mathrm{Na}_{2} \mathrm{CO}_{3}$ buffer ( $\mathrm{pH}$ 9.6). They were also blocked using 3\% skim milk powder (Merck, Darmstadt, Germany) in PBS-0.05\% Tween 20 (PBS-T) (Sigma-Aldrich), as well as Pierce ${ }^{\mathrm{TM}}$ Protein-Free (PBS) Blocking Buffer (Thermo Scientific), overnight at $4^{\circ} \mathrm{C}$. The recombinant IgG-Fc fusion proteins NKp44-Fc (2249-NK-05), NKp46-Fc (1859-NK-025), NKp30-Fc (1849-NK-025), DC-SIGN-Fc/CD209-FC (161-DC-050), DCSIGNR-Fc/CD299-FC (162-D2-050), Siglec-2-Fc (1968-SL-050), Siglec-3-Fc (1137-SL-050), Siglec-4-Fc (8940-MG-050), Siglec5-Fc (1072-SL-050), Siglec-7-Fc (1138-SL-050), Siglec-10-Fc (2130-SL-050), PSGL-1-Fc (3345-PS-050), NKG2D-Fc (1299-NK050), E-selectin-Fc (ADP1-050), P-selectin-Fc (137-LS-050), L-selectin-Fc (728-LS-100), TIM1-Fc (9319-TM-100), CD44-Fc (3360CD-050), and CD24-Fc (5247-CD-050) were obtained from R\&D (Planegg, Germany), and syndecan 1-Fc (PKSH033514) from Elabscience. All were analyzed regarding their binding ability to EBOV-GP-coated ELISA plates. All purified recombinant proteins $(1 \mu \mathrm{g} / 100 \mu \mathrm{L}$ in PBS-T with $1 \%$ bovine serum albumin) were added in triplicates to EBOV-GP-coated wells at $2 \mu \mathrm{g} /$ well for $1 \mathrm{~h}$ at room temperature. After washing 3 times with PBS-T, peroxidaseconjugated goat anti-hIgG-Fc or goat anti-mouse IgG-Fc (Dianova, Hamburg) in PBS-T (1:2,000 with $1 \%$ bovine serum albumin) was added for $1 \mathrm{~h}$ at room temperature. After washing 3 times with 
PBS-T, a peroxidase substrate solution (o-phenylenediamine [Sigma-Aldrich] at $1 \mathrm{mg} / \mathrm{mL}$ in $0.1 \mathrm{M} \mathrm{KH}_{2} \mathrm{PO}_{4}$ buffer [pH 6.0]) was added for $20 \mathrm{~min}$ at room temperature in the dark. The substrate reaction was stopped with $50 \mu \mathrm{L}$ of $4 \mathrm{~N} \mathrm{H}_{2} \mathrm{SO}_{4}$, and results were read out with a Titertek Multiscan plus MKII ELISA photometer (MP Biomedicals, Heidelberg, Germany) at OD450 $\mathrm{nm}$ and $570 \mathrm{~nm}$ for reference. The whole experiment was repeated at least 3 times.

\section{Flow Cytometry}

Flow cytometry was used to analyze binding of recombinant fusion proteins to EBOV-GP-transfected cell lines. For cell surface immunofluorescence staining, $0.5-1 \times 10^{6}$ cells were washed once in ice-cold fluorescence-activated cell sorter (FACS) buffer (D-PBS-2\% FCS) and then incubated with a saturating amount of the primary mouse MAb for $45 \mathrm{~min}$ on ice. After 2 washes, cells were incubated with PE-labeled goat anti-mouse Ig for $30 \mathrm{~min}$ on ice. Complexes of the Fc fusion proteins listed above (1-2 $\mu \mathrm{g}$ per staining) and PE-labeled goat anti-hIgG Fc (Dianova; 1:100 in FACS buffer) were allowed to form for $30 \mathrm{~min}$ before being added to cells for $60 \mathrm{~min}$ on ice. Cells were washed twice and resuspended in $200 \mu \mathrm{L}$ of FACS buffer with $0.05 \%$ propidium iodide (Sigma-Aldrich). Cytofluorometric analyses were done using a FACS Canto II or FACS LSR Fortessa flow cytometers and Diva software (Becton Dickinson, Heidelberg, Germany). For all FACS stainings, representative examples are shown from at least 3 repeats with similar results.

\section{Heparanase and Neuraminidase Treatment of Cells}

CHO-K1 transfected with pcDNA6/EBOV GP or empty pcDNA6 vector were treated with heparanase I and III (Sigma/Aldrich, $100 \mathrm{mU} / 100 \mu \mathrm{L}$ in PBS) or a2-3,6,8,9-neuraminidase (Merck/Calbiochem, $5 \mathrm{mU} / 100 \mu \mathrm{L}$ PBS) for $1 \mathrm{~h}$ at $37^{\circ} \mathrm{C}$, respectively. After enzymatic treatment and washing, cells were immediately stained on ice with Fc fusion proteins, complexed with goat anti-hIgG-PE secondary antibodies. The experiment was repeated 3 times.

\section{P24 Antigen Capture Assay}

Lentivirus particles based on the HIV-1 were produced in HEK293 cells through transient transfection of 2 plasmids encoding components of the virus envelope as described below. Cell culture medium containing viral particles produced by packaging cells was harvested after $72 \mathrm{~h}$. HEK-293 cells stably transfected with the plasmid pcDNA6/V5-HisA/EBOV-GP and control HEK-293 cells stably transfected with pcDNA6/V5-HisA were used to produce lentiviral particles displaying EBOV-GP (lenti-EBOV-GP) and control particles devoid of EBOV-GP. Briefly, $1 \times 10^{6}$ cells of each cell line were seeded in $60-\mathrm{mm}$ cell culture dishes 1 night prior to transfection. The next day, $6 \mu \mathrm{g}$ of a 3:2 ratio of lentiviral transfer vector (pLOX-CWgfp) and packaging plasmid (psPAX2) were transfected into each cell culture dish using Turbofect Transfection Reagent (Thermo Fisher Scientific). Seventy-two hours posttransfection, viral supernatants were collected and centrifuged at 3,000 $\mathrm{g}$ for 15 $\min$ at $4^{\circ} \mathrm{C}$ to remove cell debris. To concentrate the viral particles, they were centrifuged at $48,000 \mathrm{~g}$ for $3 \mathrm{~h}$ at $4^{\circ} \mathrm{C}$, and viral pellets were resuspended in cold PBS. Physical titration of the viral preparation was performed using p24 detection by sandwich ELISA. Microtiter plates precoated with anti-p24 Ab were incubated with increasing dilutions of the lentiviral suspension. After incubation and washing, p24 was quantified using a biotinylated anti-p24 Ab and detected using HRP-streptavidin. Color development was measured at $450 \mathrm{~nm}$ in a Bio-Rad spectrophotometer.

\section{ELISA (Lenti-EBOV-GP)}

Lentiviral vector titers are expressed in transducing units per mL. After physical titration of viral vectors, we immobilized HIVlentiviral EBOV-GP particles $(200 \mu \mathrm{g} / \mathrm{mL})$ on 96 -well microtiter plates (Nunc, Maxisorp) in $0.1 \mathrm{M}$ sodium bicarbonate buffer $(\mathrm{pH}$ 9.6) at $4^{\circ} \mathrm{C}$ for $18 \mathrm{~h}$ and blocked with protein-free blocking buffer (PBS) pH 7.4 (Thermo), which is recommended for viral particles with highly glycosylated proteins [47]. For the coating with EBOVGP and control lentiviral particles, equal amounts of particles were added to each well. After blocking, the plates were washed 3 times with PBS containing $0.05 \%$ Tween-20. Dilutions of $10 \mu \mathrm{g} / \mathrm{mL}$ of fusion proteins were prepared in PBS $+2 \%$ protein-free buffer, including NKp44-Fc, NKp46-Fc, NKp30-Fc, DC-SIGN-Fc, DCSIGNR-Fc, Siglec2-Fc, Siglec3-Fc, Siglec4-Fc, Siglec5-Fc, Siglec7Fc, Siglec10-Fc, PSGL-1-Fc, NKG2D-Fc, E-selectin-Fc, P-selectinFc, L-selectin-Fc, TIM1-Fc, CD44-Fc, CD24-Fc, syndecan 1-Fc (R\&D), and human anti-Gp-Fc antibody as positive control. Each protein was added in triplicate to the respective wells and incubated for $1 \mathrm{~h}$ at room temperature. After incubation, the plates were gently washed 3 times with PBS containing 0.05\% Tween-20. Then, the secondary antibody (goat anti-human IgG-Fc) was added to the wells and the plates were incubated for $1 \mathrm{~h}$ at room temperature. The plates were subsequently washed 3 times with PBS-T (PBS containing $0.05 \%$ Tween-20) and incubated with substrate (OPD) for 15-20 min. The reactions were stopped by adding 100 $\mu \mathrm{L}$ of $1 \mathrm{M}$ sulfuric acid to each well. Finally, the absorbance of $450 / 570 \mathrm{~nm}$ was measured by a BioTek Synergy 4 Multi-Mode Microplate Reader. The whole experiment was repeated twice.

\section{Statistical Analysis}

Experimental values were obtained in triplicates and repeated at least twice. The corresponding mean values with SD were used for analysis of data. Significance was tested by unpaired $t$ test with 2 -sided $p$ value. $p$ values $<0.05$ were considered significant.

\section{Results}

\section{EBOV-GP Binds NCRs, Homing Selectins, and} Inhibitory Siglecs

We used ELISA plates coated with purified recombinant EBOV-GP produced in HEK-293 cells to assess the binding to different IgG1-Fc recombinant fusion proteins (Fig. 1). In accordance with previous results [34], DC-SIGN (CD209) and its related C-type lectin DC-SIGNR (CD299) bound strongly to EBOV-GP. Also, the activating NK cell receptors NKp44 and NKp46 but not NKp30 and NKG2D showed an interaction with EBOV-GP. Furthermore, P-selectin, L-selectin (CD62 P/L), and the inhibitory receptors Siglec-5 and Siglec-7 showed significant binding to EBOVGP. However, we observed only weak or no binding of Siglec-3, E-selectin, PSGL-1, CD44, and CD24. These results were confirmed repeatedly under different conditions and with different batches of proteins, and the binding tendencies were reproducible throughout all experiments. 
Fig. 1. Binding of EBOV-GP-His-tag to activating receptors, homing proteins (selectins), and inhibitory Siglecs. ELISA plates coated with recombinant Zaire Ebola-GPHis-tag protein were used to test the binding of the indicated recombinant proteins. Each recombinant protein was added in triplicates, noncoated plates and GahIgGFc-Pox secondary antibody alone served as negative controls, and human anti-EBOV-GP antibody KZ52 as positive control. This whole test was repeated at least 5 times, with highly similar results. From these repeats, 1 representative ELISA experiment was selected for display. A significant difference between PBS controls and specific proteins was assumed when the $95 \%$ confidence limits did not overlap and the 2-sided $t$ test for paired samples was equal or lower than $p=0.05\left(p<0.05 ;\left[^{*}\right]: p=0.05\right)$. EBOVGP, Ebolavirus glycoprotein; ELISA, enzyme-linked immunosorbent assay.

Fig. 2. NCRs, homing selectins, and inhibitory Siglecs bind to EBOV-GP-transfected HEK-293 and CHO-K1 cells: HEK-293 (a) or CHO-K1 (b) cells were stably transfected with EBOV-GP or with empty vector as control. GP expression efficiency was detected by anti-ZEBOV GP human antibody KZ52. The insets show peaks derived from the original flow cytometry analyses consisting of at least 3 repeats, which indicate the binding of the respective fusion proteins to EBOV-GP-transfected HEK-293 (a) or CHO-K1 (b) cells in relation to their binding to the vector control-transfected cells. Significance was calculated by 2 -sided $t$ test for paired samples, comparing the binding of recombinant proteins to vectorand GP-transfected cells. $(*): p<0.1 ; *: p<$ $0.05 ; * *: p<0.001$. EBOV-GP, Ebolavirus glycoprotein; NCRs, natural cytotoxicity receptors.
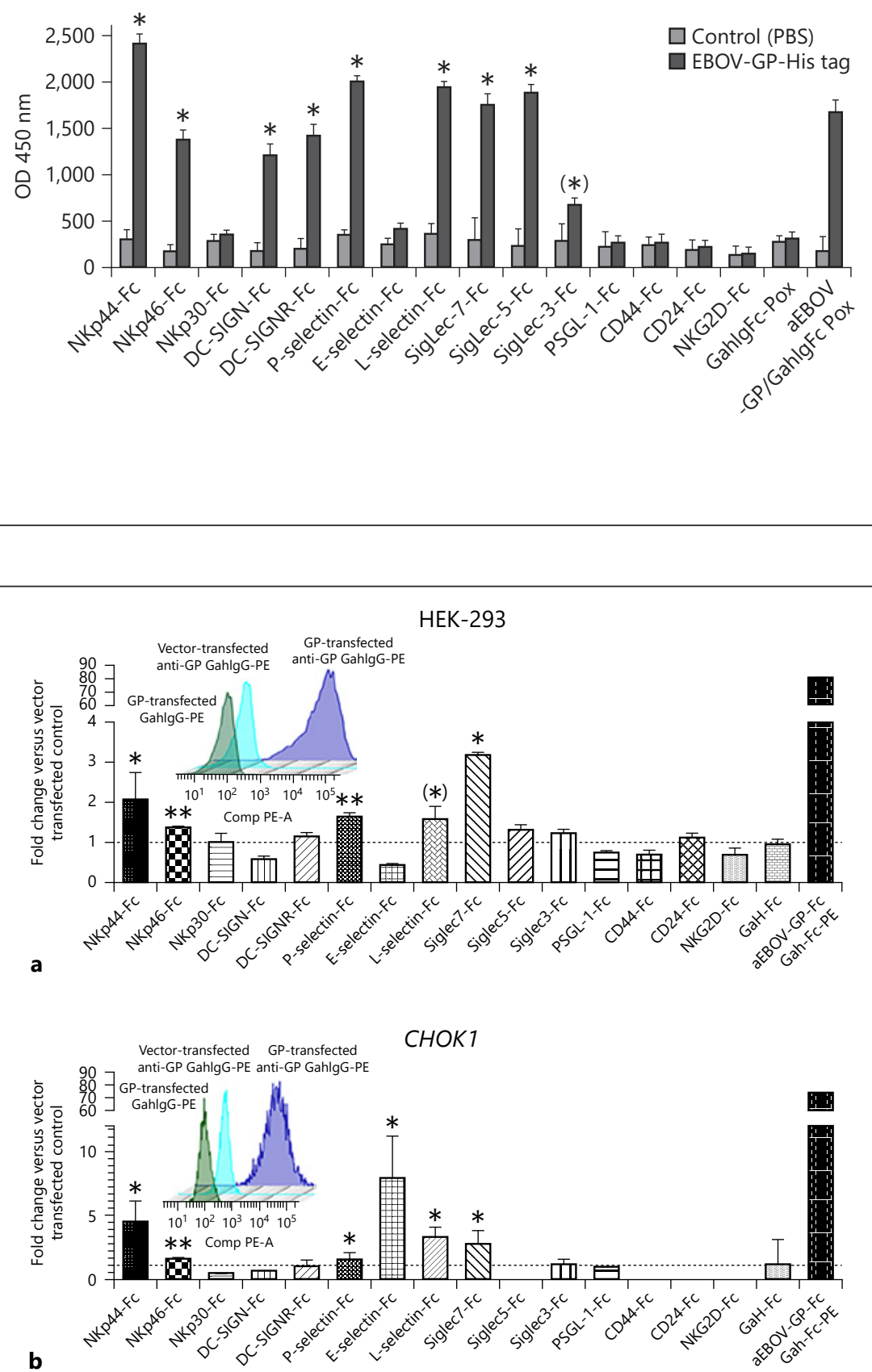

Interactions with EBOV-GP Expressed in HEK-239 and $\mathrm{CHO}-\mathrm{K} 1 \mathrm{Cells}$

To confirm these interactions in a cellular context, we stably transfected HEK-239 cells with plasmids carrying the EBOV-GP gene. GP expression efficiency was con- firmed using the human monoclonal anti-ZEBOV GP antibody KZ52 [46] (Fig. 2a). We then used the various Fc fusion proteins for immunofluorescence staining of the transfected HEK-293 ${ }^{\mathrm{EBOV}-G P}$ cells and analyzed the binding by flow cytometry (Fig. 2a; online suppl. Fig- 


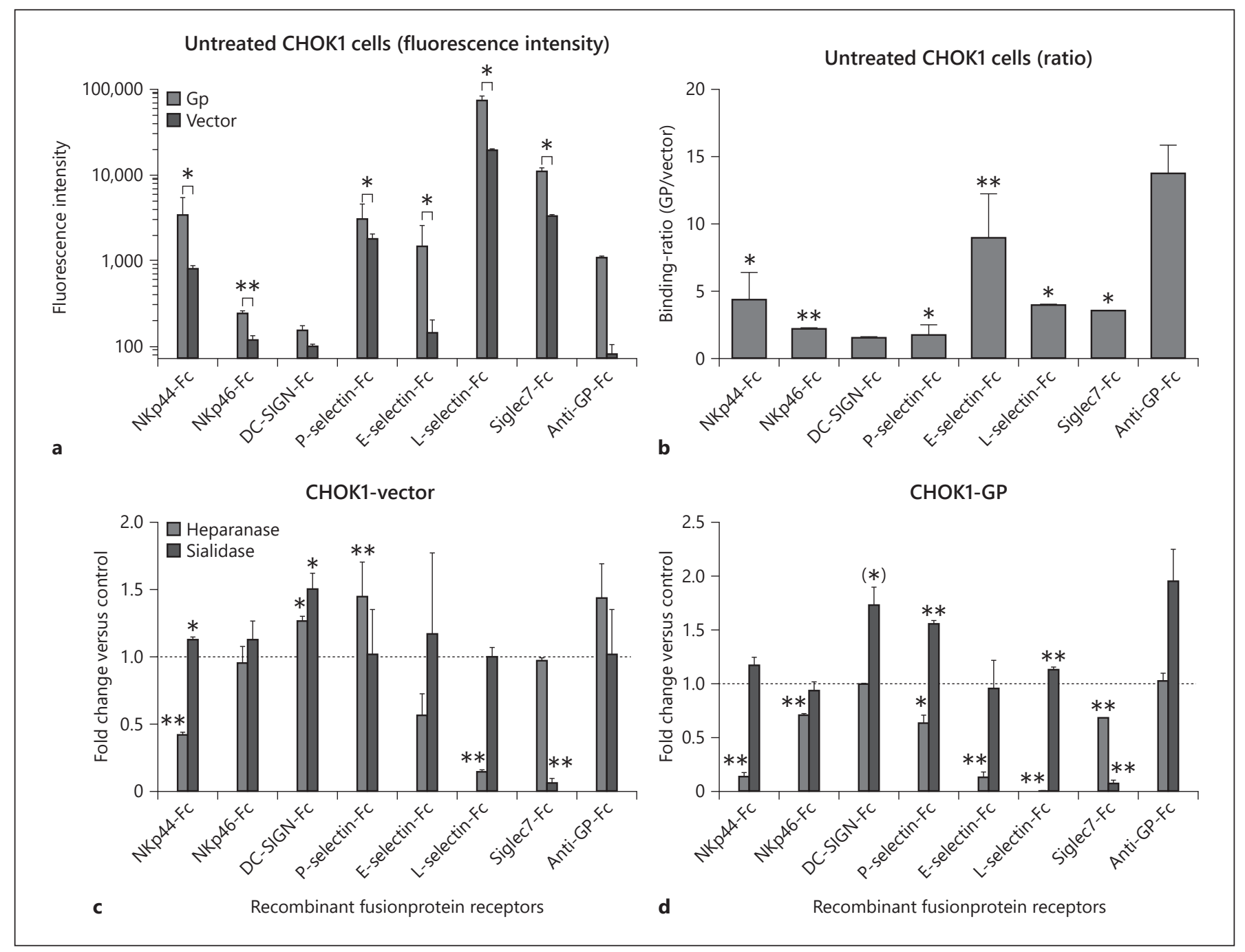

Fig. 3. Treatment of EBOV-GP-transfected CHO-K1 cells with heparanase I and III or sialidase. EBOV-GP- or vector controltransfected $\mathrm{CHO}-\mathrm{K} 1$ cells were pretreated with heparinase I and III, or sialidase, or left untreated as a control. The binding of the indicated fusion proteins to the differential treated cells was analyzed by at least 2 experiments. Shown are the fluorescence intensities for binding (a), the corresponding s ratios of GP- and vectortransfected $\mathrm{CHO}-\mathrm{K} 1$ cells $(\mathbf{b})$ in relation to the respective ratio in binding to vector control- (c) and GP-transfected (d) cells, which had been pretreated with either heparinase or sialidase. Significance was calculated by 2 -sided $t$ test for paired samples, comparing the binding of recombinant proteins to vector- and GP-transfected cells. $\left(^{*}\right): p<0.1 ; *: p<0.05 ;{ }^{* *}: p<0.001$. These results were also used for indicating significance of ratios. EBOV-GP, Ebolavirus glycoprotein. ure 1; see www.karger.com/doi/10.1159/000517628 for all online suppl. material). Similar to our results with EBOV-GP-coated ELISA plates, we observed significantly enhanced binding of recombinant NKp44-Fc, NKp46-Fc, L-selectin-Fc, P-selectin-Fc, Siglec-7-Fc, and Siglec-5-Fc proteins to HEK-293 ${ }^{\mathrm{EBOV}-\mathrm{GP}}$ cells in comparison to vector control-transfected cells. However, we could not confirm the binding of DC-SIGN-Fc and DC-SIGNR-Fc. Siglec-3, which only showed weak binding to the EBOV-GP-coat- ed ELISA plates, exhibited similar binding in this cellular assay. For NKp30-Fc, NKG2D-Fc, E-selectin-Fc, PSGL$1-\mathrm{Fc}, \mathrm{CD} 44-\mathrm{Fc}$, and CD24-Fc, we observed no increased binding to HEK-293 ${ }^{\text {EBOV-GP }}$ cells exceeding the staining of endogenous ligands expressed by HEK-293 vectortransfected controls, confirming the ELISA results. Extending this analysis, we also did not observe enhanced binding of recombinant Siglec-2-Fc, Siglec-4-Fc, Siglec10-Fc, L1-CAM-Fc, or TIM-1-Fc proteins to HEK- 


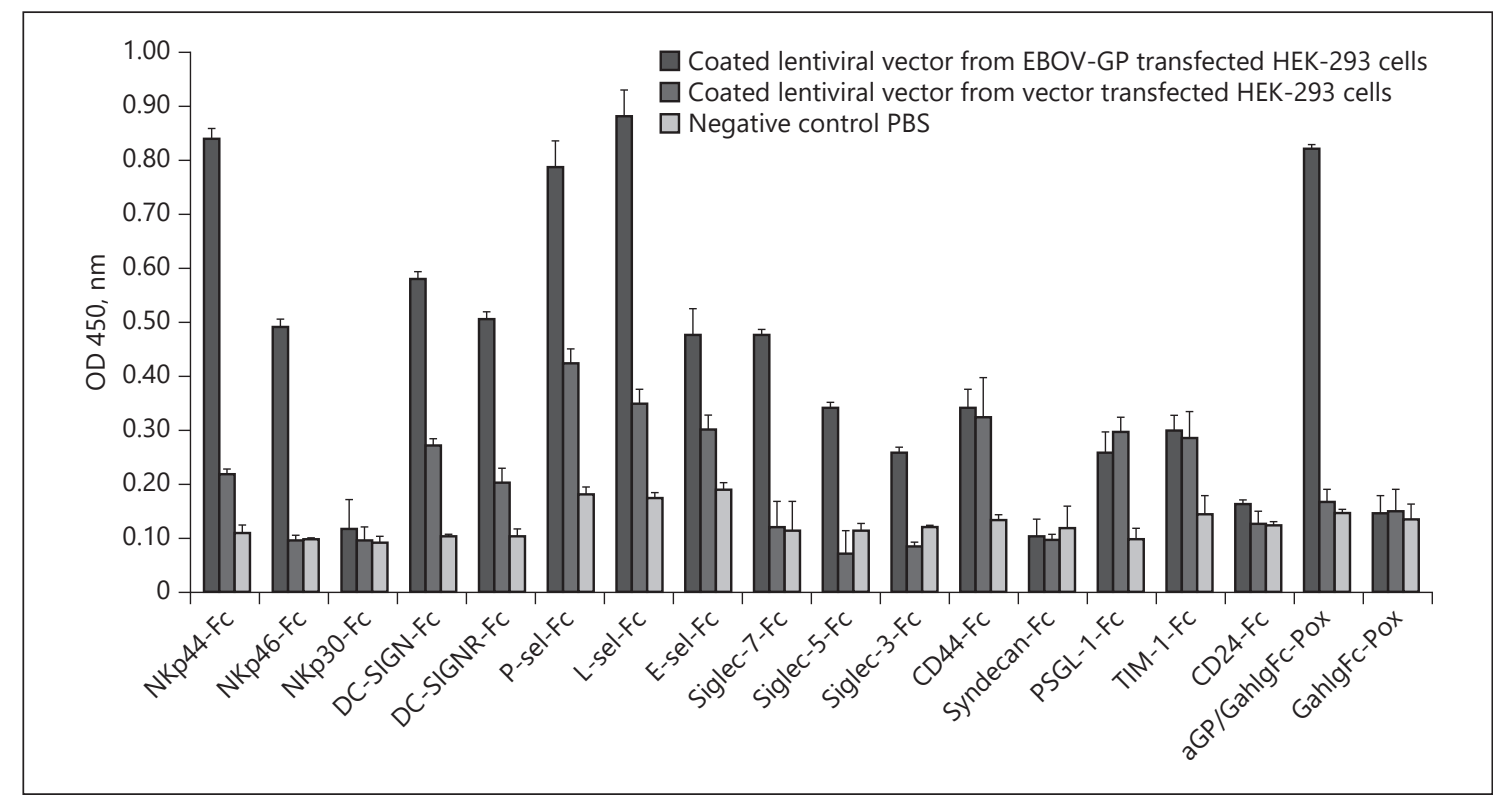

Fig. 4. Binding of fusion proteins to lentiviral particles displaying EBOV-GP. ELISA plates were coated with lentiviral particles originating from EBOV-GP- or vector control-transfected HEK-293 cells or with PBS as a control. The coating efficiency was determined by anti-ZEBOV GP monoclonal antibody KZ52. The binding of the indicated fusion proteins to the coated ELISA plates was analyzed. The experiment was performed in triplets and repeated twice. EBOV-GP, Ebolavirus glycoprotein; ELISA, enzyme-linked immunosorbent assay.

$293^{\text {EBOV-GP }}$ cells (data not shown). Interestingly, we even observed reduced binding of some fusion proteins when comparing HEK-293 ${ }^{\mathrm{EBOV}-\mathrm{GP}}$ to vector control-transfected cells. For example, binding of NKG2D to its cellular ligands was reduced in GP-transfected HEK-293 cells, which suggests a reduced availability of its ligands MIC$\mathrm{A} / \mathrm{B}$, as it has been demonstrated before [48].

In addition to the HEK-293 ${ }^{\mathrm{EBOV}-\mathrm{GP}}$ cells, we used EBOV-GP-transfected CHO-K1 cells to assess the binding of some of the recombinant fusion proteins to EBOV-GP in a nonhuman cell line (Fig. 2b and online suppl. Fig. 2). HEK-293 and CHO share similar posttranslational protein modifications in the endoplasmic reticulum and Golgi apparatus [49]. More importantly, CHO cells are able to produce complex types of recombinant proteins with human-compatible glycosylation. $\mathrm{CHO}$ cells, however, do not express Gal $\alpha-2,6$-sialyltransferase, $\alpha-1,3 / 4$ fucosyltransferase, or $\beta-1,4-N$-acetylglucosaminyltransferase III (GnT-III), which are enzymes expressed in human cells [50-52]. In agreement with the previous results, we found enhanced binding of NKp44-Fc, NKp46Fc, L-selectin-Fc, P-selectin-Fc, and Siglec-7-Fc to EBOV-GP-transfected CHO-K1 cells. Again, DC-SIGN-Fc and DC-SIGNR-Fc did not show significant binding compared to control cells in this cellular assay. Also, we found no enhanced binding of PSGL-1-Fc, NKp30-Fc, and Siglec-3-Fc, which is in agreement with the results of the ELISAs. However, in contrast to results mentioned above we observed strongly enhanced binding of E-selectin to EBOV-GP-transfected $\mathrm{CHO}-\mathrm{K} 1$ cells. In summary, the cellular assays confirmed NKp44, NKp46, L-selectin, P-selectin, Siglec-7, and Siglec-5 as binding partners for EBOV-GP.

\section{Binding of the Chimeric Soluble Receptors to Their} Ligands Depends on Sialic Acid and Heparan Sulfate

$\mathrm{P}$ - and L-selectin recognize clustered sulfated $O$-sialoglycan epitopes, for example, on the proteoglycan CD44. L-selectin, like other selectins, recognizes sialylated Lewis ${ }^{\mathrm{x}}$ and sialylated Lewis ${ }^{\mathrm{a}}$ glycans (sLe ${ }^{\mathrm{a}}$; Neu5Aca23Gal $\beta 1-3$ [Fuca 1-4] GlcNAc) [53, 54]. All 3 selectins recognize sulfated and sialylated derivatives [54]. In addition, L-selectin binds to O-glycosylated proteins [55]. Many enveloped viruses, for instance, influenza virus and Newcastle disease virus (NDV), bind to sialic acid residues located on the surface of target cells [32]. In order to analyze the involvement of sialic acid and heparan sulfate moieties in the binding of the fusion proteins to EBOVGP-transfected CHO-K1 cells, we treated the GP- and mock-transfected cells with heparanases I and III, and si- 


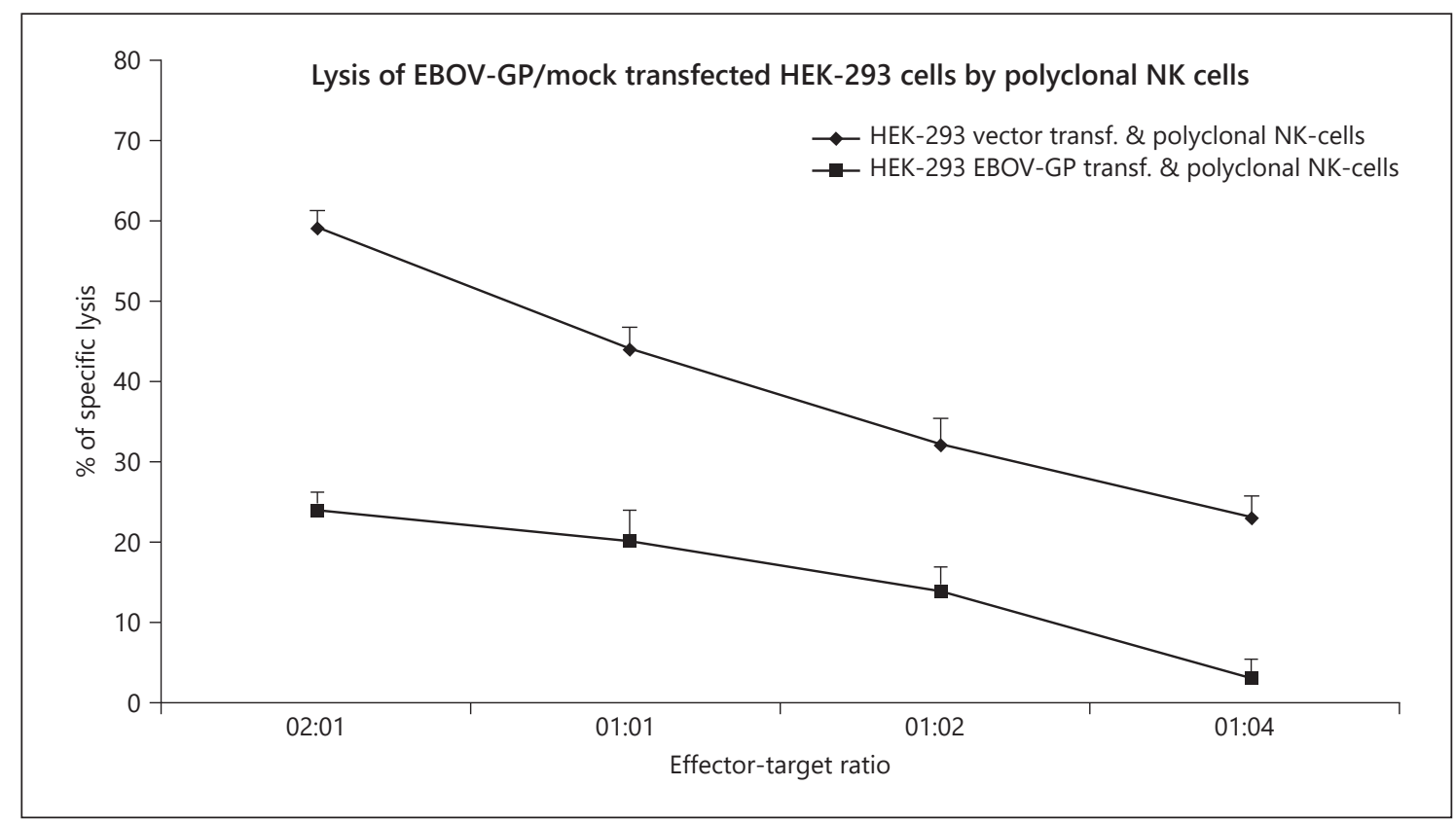

Fig. 5. Killing of HEK-293 $3^{\mathrm{EBOV}-\mathrm{GP}}$ target cells by polyclonal NK cells. HEK-293 target cells transfected with empty vector as a control or with EBOV-GP were incubated with polyclonal human NK cells at the indicated effector to target ratios. Lysis of the HEK-293 cells was analyzed using a standard $4 \mathrm{~h}{ }^{51} \mathrm{Cr}$ release assay. The experiment was performed in triplets and repeated twice. EBOV-GP, Ebolavirus glycoprotein; NK, natural killer.

alidase. Interestingly, GP-transfected cells showed increased binding in terms of median fluorescence intensity of all fusion proteins shown compared to vector control cells (Fig. 3 top and online suppl. Fig. 3). Following treatment, we analyzed the impact of these enzymes on the binding of fusion proteins to EBOV-GP- and mocktransfected CHO-K1 cells (Fig. 3, middle and bottom; and online suppl. Fig. 3). Treatment with heparanase resulted in a significantly decreased binding of selectins to EBOV-GP-transfected CHO-K1 cells. Similarly, binding of NKp44 and NKp46 was reduced following heparanase treatment, as was expected since it is known that heparan sulfate is a ligand for these receptors $[22,23]$. In contrast, binding of Siglec-7 was less (though still significantly) affected by heparanase, yet strongly sensitive to sialidase I/ III treatment, which reduced its binding significantly by more than $90 \%$, as can be explained by the fact that sialic acid is the main ligand of Siglecs.

\section{Binding of Fusion Proteins to Lentiviral Particles \\ Displaying EBOV-GP}

The GP glycoprotein serves the EBOV to infect host cells by binding to various docking proteins. After transduction, viruses can incorporate or co-package many hosts cell-derived nonviral surface proteins into their newly formed envelope [56-58]. Lately, this was demonstrated for infectious clones of HIV-1 propagated in HEK-293T cells [59]. We therefore produced recombinant lentiviral particles in HEK-293 cells stably transfected either with EBOV-GP or empty vector control. After concentrating the lentiviral particles, they were used for coating ELISA plates and coating efficiency was confirmed using an anti-GP antibody (Fig. 4). We then tested the binding of the different fusion proteins to the coated lentiviral particles (Fig. 4). We found significant binding to lenti-EBOV-GP by NKp44-Fc, NKp46-Fc, E-selectinFc, L-selectin-Fc, P-selectin-Fc, Siglec-7-Fc, Siglec-5-Fc, Siglec-3-Fc, DC-SIGN-Fc, and DC-SIGNR-Fc, essentially confirming our previous results. Consistent with experiments reported above, we found no binding of NKp30-Fc, CD24-Fc, or syndecan-1-Fc to the lenti-EBOV-GP. TIM-1-Fc bound to the lentiviral particles irrespective of their content of EBOV-GP. This may be due to the fact that TIM-1 binds to PtdSer, which originated from the cell surface of host HEK-293 cells and was taken up by the virus envelope [57]. Likewise, CD44-Fc and PSGL-1-Fc interacted with vector envelopes independent of GP expression, which can be explained by their binding to cellular ligands from the host plasma membrane, which were taken up by the lentiviral envelopes. 
HPV-L1 Binds NCRs, Selectins, and Inhibitory Siglecs

To investigate if the proteins that we found to interact with EBOV-GP also bind to other viral surface proteins, we assessed the binding of the fusion proteins to purified human papillomavirus (HPV)-L1 virus-like particles (online suppl. Fig. S4). Interestingly, we observed specific binding of NKp44-Fc, NKp46-Fc, P-selectin-Fc, L-selectin-Fc, Siglec-7-Fc, and Siglec-5-Fc and no binding of NKp30-Fc, DC-SIGN-Fc, DC-SIGNR-Fc, E-selectin-Fc, Siglec-3-Fc, or PSGL-1-Fc, a pattern which was similar to the binding to EBOV-GP-pseudotyped lentiviral particles.

\section{EBOV-GP Protects HEK-293 Cells from Lysis by} Polyclonal NK Cells

Our data show that many NK cell receptors can interact with EBOV-GP. Therefore, we wanted to test how the expression of GP can influence the killing of target cells by NK cells. We used HEK-293 ${ }^{\mathrm{EBOV}-\mathrm{GP}}$ or mock-transfected HEK-293 cells as targets for primary NK cells obtained from different donors in a ${ }^{51} \mathrm{Cr}$ release assay. As shown in Figure 5, HEK-293 ${ }^{\text {EBOV-GP }}$ cells were significantly less susceptible to NK cell-mediated lysis compared to mock-transfected cells, suggesting that the pleiotropic effects of EBOV-GP on the cell surface have an overall suppressive result on NK cells. Altogether, these results suggest a crucial role of EBOV-GP in mediating immune escape of transduced/infected cells.

\section{Discussion/Conclusion}

Our data show that EBOV-GP binds to the chimeric soluble proteins L- and P-selectin, Siglec-7 and Siglec-5, NKp44 and NKp46, and, to a lesser extent, to Siglec-3, DCSIGN, and DC-SIGNR, which are known cellular receptors for EBOV [37, 39, 60-62]. We were able to demonstrate the binding of DC-SIGN-Fc and DC-SIGNR-Fc to purified recombinant EBOV-GP on ELISA plates, but not to HEK$293^{\mathrm{EBOV}-\mathrm{GP}}$ cells. A possible explanation is that EBOV-GP, which is highly glycosylated in human host cells, interacts with neighboring surface proteins. This, in turn, will block many epitopes, which are recognized by recombinant fusion proteins, including DC-SIGN-Fc and DC-SIGNR-Fc. In contrast, $\mathrm{GP}$ on the viral envelope remains free for interaction with both proteins. Like the HIV-1 gp120, the highly glycosylated EBOV-GP utilizes the C-type lectin receptor DC-SIGN (CD209) to infect dendritic cells, which are a major reservoir of EBOV [60-62]. We could not prove binding of TIM-1-Fc to HEK-293 ${ }^{\text {EBOV-GP }}$ cells or to purified EBOV-
GP, yet we showed binding of TIM-1-Fc to lentiviral particles displaying EBOV-GP on their envelope (lenti-EBOVGP), as well as to mock lentiviral particles. The binding of TIM-1-Fc to lentiviral particles irrespective of their content of EBOV-GP is due to the fact that TIM-1 binds to cohesive PtdSer, which was incorporated by the virus envelope. It originates from the inner plasma membrane of mock- or EBOV-GP-transfected HEK-293 cells [57]. TIM-3, TIM-4, and TIM-1 together inhibit HIV and EBOV release from infected cells [63]. TIM-1 also serves as a pattern recognition receptor on invariant NK cells, which mediate cell activation by TIMs binding to PtdSer on the surface of cells undergoing apoptosis [64]. It is likely that TIM-3, an inhibitory checkpoint receptor on effector cells, binds also to PtdSer of the EBOV envelope $[41,42]$. We hypothesize that the integration of PtdSer into the virus envelope plays also a role in infected patients. Here, TIMs will elicit eventually a strong reaction (cytokine storm) when they are triggered by their ligand PtdSer. This will depend on the amount of PtdSer available and on the activation of stimulating receptors, which can cause that TIMs act as costimulatory receptors [65]. For NK cells, this can imply that the inhibitory activity caused by interaction of GP with Siglecs is diminished, and thus they contribute to the uncontrolled cytokine storm that has been observed after Ebola infection. This assumption is in line with reports showing a better survival of TIM1 double-knockout mice, which showed reduced cytokine release and better survival after infection with EBOV [66].

Our data show that L-and $\mathrm{P}$-selectins and possibly also E-selectin bind to purified EBOV-GP coated on ELISA plates and to EBOV-GP-transfected cells (HEK-293 and $\mathrm{CHO}-\mathrm{K} 1)$. This is in line with recently published data that the viral particle gp120 of HIV-1 binds L-selectin (CD62L) $[43,44,53,67]$. Similarly, human P-selectin glycoprotein ligand-1 is a functional receptor for enterovirus 71 [68]. Therefore, we believe that selectins play an important role in EBOV release from infected cells, as it has been shown for HIV, which binds L-selectin and CD34 to co-localize with ADAM17 [43, 44, 53, 67].

Siglecs often function as sensor for sialylated glycoproteins. Through their intracellular ITIM, they induce strong inhibitory signaling upon binding to different linkages of sialic acid [69]. Interestingly, this mechanism is used by tumor cells and pathogens to escape the immune system, by adding sialic acid residues to their glycan structures, thus highlighting that the sialic acid-Siglec interaction is key to the immune function against pathogens and cancer [70, 71]. NK and other effector cells express various Siglecs, for example, Siglec-3, 7, 8, and $9[72$, 
73]. We observed binding of Siglec-7 and -5 to EBOV-GP in ELISA as well as to CHO-K1 EBOV-GP-transfected cells and lentiviral particles. Siglec-7 binding to EBOVGP-transfected CHO-K1 is dependent on 2,6-sialic acid linkage, since treatment with sialidase reverts the binding. We have not tested Siglec-8 and Siglec-9, but assume that Siglec- 8 and Siglec- 9 might also bind to GP because of their similar avidity for 2,6- and 2,3-sialic acid linkages. In addition, they are MHC class I-independent inhibitory receptors on immune effector cells, which - when stimulated - prevent the activation of these cells.

The current study shows that Ebola-GP binds to several immune receptors. Notably, the binding differs between the principal assays: for example, EBOV-GP-overexpressing HEK-293 cells do not bind to E-selectin-Fc, while CHO-K1 cells bind strongly (Fig. 2). This might be explained by differences in the nature of these cells. EBOV-GP is highly glycosylated and therefore undergoes strong interactions in cis. As a consequence, there can be massive rounding and detachment of infected/transfected cells [74-76]. Concomitantly, the expression of receptors differs qualitatively and quantitatively between human HEK-293 and hamster CHO-K1 cells. Further, there are differences in glycosylation and accessibility of these receptors. Finally, human cells are more susceptible for EBOV infection than hamster cells. All these factors contribute to a (slightly to pronounced) different binding behavior of our recombinant proteins. For all these reasons, the binding behavior differs between cell lines from 2 different species.

NK cells are effector cells of the early innate immune response that play a critical role in the lysis of virus-infected cells and tumor cells without requiring prior antigen stimulation $[77,78]$. We and others have previously shown the interaction of NCRs with HA-neuraminidase of NDV, poxviral HA, and influenza viruses [24, 29, 32]. Recently, it was reported that blocking NKp30 by a specific antibody reduced lysis of EBOV-infected dendritic cells by NK effector cells [14]. Our data show that NKp44 and NKp46 but not NKp30 directly bound with EBOVGP if tested as soluble hIgG1 fusion proteins, while all 3 NCR Fc fusion proteins stained endogenous ligands on control cells. This interaction was likely dependent on heparan sulfate as it was reduced by heparinase treatment (see Fig. 4). Heparan sulfate binds many microorganisms and interacts with many viral envelope components, for example, from HIV-1 [79], hepatitis viruses [80, 81], flaviviruses [82, 83], vaccinia virus [84], HPV [85], human herpesvirus [86], HSV-1 [87], and EBOV [88]. The binding of NCRs to EBOV-GP as well as other viral envelope proteins led us to examine their binding also to HPV-L1.
NKp44 and P- and L-selectins showed strong binding to HPV-L1, while NKp46 and Siglec-5 and Siglec-7 showed low binding. Therefore, we hypothesized that NK cell receptors play a key role in the recognition of structural glycoproteins of virtually any virus by NK effector cells and thus facilitate the elimination of pathogens.

The mechanism by which EBOV-GP modulates the activity of NK cells may simultaneously involve (i) the binding of different inhibitory Siglecs, (ii) the interaction with the activating receptors NKp44 and NKp46, and (iii) a reduction of NKG2D ligands (MICA/B) as we observed a lower binding of NKG2D-Fc chimeric soluble receptors to EBOV-GP-transfected HEK-293 cells, as has been reported before [48]. The net result of the expression of EBOV-GP by HEK-293 cells was a reduction in NK cell-mediated lysis. This suggests that the reduced stimulation of NKG2D together with the engagement of inhibitory Siglecs outweighs the binding to the activating receptors NKp44 and NKp46.

For the observed cell growth inhibition of NK cells in response to EBOV-GP interaction, the binding to inhibitory Siglec receptors (e.g., Siglec-7 or Siglec-9) is decisive. In mock-transfected HEK cells, only heparan sulfate chains of proteoglycans, including CD44, will interact with NKp44 or NKp46 receptors of NK cells and thus activate them, which leads to an efficient cell kill. In GPtransfected cells, these groups are also available, but they are engaged by the cis interaction with GP. Therefore, these glycoproteins are less active in the interaction with activating receptors on NK cells, for example, NCRs and L-selectin. In addition, GP proteins bind with high affinity to inhibitory receptors, such as Siglecs. This causes an altered balance of activating and inhibitory receptors and in summary reduces the activation of NK cells. However, these thoughts are to be complemented with experiments involving the blockade of NK cell cytolytic activity to explore how the sublying forces act together.

The reduced cell kill activity caused by the altered balance in NK cells based on activating and inhibitory receptors will be explored by blocking experiments in the future. The interaction of highly glycosylated GP in cis with other proteoglycans and their heparan sulfate chains will influence the interaction between target and effector cells (NK cells). Although it has been described that infection with $\mathrm{EBOV}$ is able to induce massive NK apoptosis, thus avoiding NK function and impairing NK-mediated effects [89], we have not observed massive apoptosis in our NK cells. We can only speculate that the GP load on our transfected HEK cells was lower than that of cells infected with the wild-type virus [24], which helped the NK cells to avoid induction of apoptosis. 
To explain the reduced killing of GP-infected cells by NK cells (Fig. 5), we hypothesize that GP may interact in cis with certain adhesion molecules by binding to their heparan-sulfate chains. This is important, as in mocktransfected HEK-293 cells the heparan sulfate chains of proteoglycans, including CD44, will interact with NKp44 or NKp46 receptors of NK cells and thus activate them, which leads to an efficient cell kill. However, when engaged by the cis interaction with GP, these glycoproteins are less active in the interaction with activating receptors on NK cells, for example, NCRs and L-selectin. In addition, GP proteins bind with high affinity to inhibitory receptors, such as Siglec-3 or Siglec-7. This causes an altered balance of activating and inhibitory receptors and in summary reduces the activation of NK cells and thus prevents interaction and subsequent polarization of effector cells with their virus-infected targets. Alternatively, the blockade of receptors responsible for apoptosis induction may also be the reason for reduced killing of infected target cells, as described for filovirus particles [90]. More in-depth knowledge about the mechanisms by which EBOV-GP-expressing cells are able to directly switch off NK cell functions will certainly be helpful to develop an efficient therapy for EBOV infections [91].

Finally, we propose a possible therapeutic treatment for EBOV infections. We hypothesize that an anti-GP antibody retargeted to neuraminidase activity could reduce the virus's sialylation, thus reducing the binding to inhibitory Siglecs of immune effector cells and increasing the recognition of their activating receptor NCRs (see Fig. 4). This will bring about a higher sensitivity toward immune effector cells. Such a therapeutic approach is certainly interesting and must be followed up by future experiments.

\section{Acknowledgment}

We are thankful to Professor Stephan Becker (Institute of Virology, Philipps-University, Marburg) for kindly providing pCAGGS/ZEVOV-GP plasmid.

\section{Statement of Ethics}

Not applicable because only laboratory experiments are described.

\section{Conflict of Interest Statement}

The authors declare no conflict of interest.

\section{Funding Sources}

This work received no funding.

\section{Author Contributions}

M.J. conceptualized, planned, and performed the experiments, reviewed the literature, and drafted the manuscript. F.M. designed the plasmid constructs. C.W. supervised the research and wrote the MS. L.K.B. performed the killing assay. K.A., R.A., and M.H.E. performed the antigen capture assay. A.K. edited the figures. M.R.B. supervised the research and statistical analysis. A.C.A., K.M., and N.B. all authors contributed equally in reading and editing the MS.

\section{References}

1 Bray M, Mahanty S. Ebola hemorrhagic fever and septic shock. J Infect Dis. 2003;188(11): $1613-7$

2 Feldmann H, Geisbert TW. Ebola haemorrhagic fever. Lancet. 2011;377(9768):849-62.

3 Licata JM, Johnson RF, Han Z, Harty RN. Contribution of ebola virus glycoprotein, nucleoprotein, and VP24 to budding of VP40 viruslike particles. J Virol. 2004;78(14):7344-51.

4 Mulangu S, Dodd LE, Davey RT Jr, Tshiani Mbaya O, Proschan M, Mukadi D, et al. A randomized, controlled trial of ebola virus disease therapeutics. N Engl J Med. 2019; 381(24):2293-303.

5 Barrientos LG, Martin AM, Rollin PE, Sanchez A. Disulfide bond assignment of the Ebola virus secreted glycoprotein SGP. Biochem Biophys Res Commun. 2004;323(2):696-702.
6 Falzarano D, Krokhin O, Wahl-Jensen V, Seebach J, Wolf K, Schnittler HJ, et al. Structurefunction analysis of the soluble glycoprotein, sGP, of Ebola virus. Chembiochem. 2006; 7(10):1605-11.

7 Sanchez A, Yang ZY, Xu L, Nabel GJ, Crews T, Peters CJ. Biochemical analysis of the secreted and virion glycoproteins of Ebola virus. J Virol. 1998;72(8):6442-7.

8 Stroher U, West E, Bugany H, Klenk HD, Schnittler HJ, Feldmann H. Infection and activation of monocytes by Marburg and Ebola viruses. J Virol. 2001;75:11025-33.

9 Klenk HD, Feldmann H. Symposium on Marburg and Ebola viruses. Virus Res. 2001;80: 117-123.
10 Trefry JC, Wollen SE, Nasar F, Shamblin JD, Kern SJ, Bearss JJ, et al. Ebola virus infections in nonhuman primates are temporally influenced by glycoprotein poly-U editing site populations in the exposure material. Viruses. 2015;7(12):6739-54.

11 Jeffers SA, Sanders DA, Sanchez A. Covalent modifications of the ebola virus glycoprotein. J Virol. 2002;76(24):12463-72.

12 Zhang X, Wang C, Chen B, Wang Q, Xu W, Ye $S$, et al. Crystal structure of refolding fusion core of Lassa virus GP2 and design of Lassa virus fusion inhibitors. Front Microbiol. 2019;10:1829.

13 Hastie KM, Zandonatti MA, Kleinfelter LM, Heinrich ML, Rowland MM, Chandran K, et al. Structural basis for antibody-mediated neutralization of Lassa virus. Science. 2017; 356(6341):923-8. 
14 Fuller CL, Ruthel G, Warfield KL, Swenson DL, Bosio CM, Aman MJ, et al. NKp30-dependent cytolysis of filovirus-infected human dendritic cells. Cell Microbiol. 2007;9(4): 962-76.

15 Galandrini R, Palmieri G, Piccoli M, Frati L, Santoni A. Role for the Racl exchange factor Vav in the signaling pathways leading to NK cell cytotoxicity. J Immunol. 1999;162(6): 3148-52.

16 Villalba M, Hernandez J, Deckert M, Tanaka Y, Altman A. Vav modulation of the Ras/ MEK/ERK signaling pathway plays a role in NFAT activation and CD69 up-regulation. Eur J Immunol. 2000;30(6):1587-96.

17 Bosio CM, Aman MJ, Grogan C, Hogan R, Ruthel G, Negley D, et al. Ebola and Marburg viruses replicate in monocyte-derived dendritic cells without inducing the production of cytokines and full maturation. J Infect Dis. 2003;188(11):1630-8.

18 Melanson VR, Kalina WV, Williams P. Ebola virus infection induces irregular dendritic cell gene expression. Viral Immunol. 2015;28(1): $42-50$.

19 Mahanty S, Gupta M, Paragas J, Bray M, Ahmed R, Rollin PE. Protection from lethal infection is determined by innate immune responses in a mouse model of Ebola virus infection. Virology. 2003;312(2):415-24.

20 Moretta L, Moretta A. Unravelling natural killer cell function: triggering and inhibitory human NK receptors. EMBO J. 2004;23(2): 255-9.

21 Byrd A, Hoffmann SC, Jarahian M, Momburg F, Watzl C. Expression Analysis of the ligands for the natural killer cell receptors NKp30 and NKp44. PLos One. 2007;2(12):e1339.

22 Hecht ML, Rosental B, Horlacher T, Hershkovitz O, De Paz JL, Noti C, et al. Natural cytotoxicity receptors NKp30, NKp44 and NKp46 bind to different heparan sulfate/heparin sequences. J Proteome Res. 2009;8(2): 712-20.

23 Hershkovitz O, Jarahian M, Zilka A, Bar-Ilan A, Landau G, Jivov S, et al. Altered glycosylation of recombinant NKp30 hampers binding to heparan sulfate: a lesson for the use of recombinant immunoreceptors as an immunological tool. Glycobiology. 2008;18(1):2841.

24 Jarahian M, Fiedler M, Cohnen A, Djandji D, Hämmerling GJ, Gati C, et al. Modulation of NKp30- and NKp46-mediated natural killer cell responses by poxviral hemagglutinin. PLoS Pathog. 2011;7(8):e1002195.

25 Arnon TI, Achdout H, Levi O, Markel G, Saleh N, Katz G, et al. Inhibition of the NKp30 activating receptor by pp65 of human cytomegalovirus. Nat Immunol. 2005;6(5):51523.

26 Pende D, Parolini S, Pessino A, Sivori S, Augugliaro R, Morelli L, et al. Identification and molecular characterization of NKp30, a novel triggering receptor involved in natural cytotoxicity mediated by human natural killer cells. J Exp Med. 1999;190(10):1505-16.
27 Delahaye NF, Rusakiewicz S, Martins I, Ménard C, Roux S, Lyonnet L, et al. Alternatively spliced NKp30 isoforms affect the prognosis of gastrointestinal stromal tumors. Nat Med. 2011;17(6):700-7.

28 Bar-On Y, Charpak-Amikam Y, Glasner A, Isaacson B, Duev-Cohen A, Tsukerman P, et al. NKp46 recognizes the sigmal protein of reovirus: implications for reovirus-based cancer therapy. J Virol. 2017;91(19):91.

29 Mandelboim O, Lieberman N, Lev M, Paul L, Arnon TI, Bushkin Y, et al. Recognition of haemagglutinins on virus-infected cells by NKp46 activates lysis by human NK cells. Nature. 2001;409(6823):1055-60.

30 Gazit R, Gruda R, Elboim M, Arnon TI, Katz $\mathrm{G}$, Achdout $\mathrm{H}$, et al. Lethal influenza infection in the absence of the natural killer cell receptor gene Ncr1. Nat Immunol. 2006; 7(5):51723.

31 Arnon TI, Lev M, Katz G, Chernobrov Y, Porgador A, Mandelboim O. Recognition of viral hemagglutinins by NKp44 but not by NKp30 Eur J Immunol. 2001;31(9):2680-9.

32 Jarahian M, Watzl C, Fournier P, Arnold A, Djandji D, Zahedi S, et al. Activation of natural killer cells by Newcastle disease virus hemagglutinin-neuraminidase. J Virol. 2009; 83(16):8108-21.

33 Hershkovitz O, Rosental B, Rosenberg LA, Navarro-Sanchez ME, Jivov S, Zilka A, et al. NKp44 receptor mediates interaction of the envelope glycoproteins from the West Nile and dengue viruses with NK cells. J Immunol. 2009;183:2610-21.

34 Gramberg T, Soilleux E, Fisch T, Lalor PF, Hofmann $\mathrm{H}$, Wheeldon $\mathrm{S}$, et al. Interactions of LSECtin and DC-SIGN/DC-SIGNR with viral ligands: differential $\mathrm{pH}$ dependence, internalization and virion binding. Virology. 2008;373(1):189-201.

35 Khoo US, Chan KY, Chan VS, Lin CL. DCSIGN and L-SIGN: the SIGNs for infection. J Mol Med. 2008;86(8):861-74.

36 Nabatov AA, Raginov IS. The DC-SIGNCD56 interaction inhibits the anti-dendritic cell cytotoxicity of CD56 expressing cells. Infect Agent Cancer. 2015;10:49.

37 Kondratowicz AS, Lennemann NJ, Sinn PL, Davey RA, Hunt CL, Moller-Tank S, et al. Tcell immunoglobulin and mucin domain 1 (TIM-1) is a receptor for Zaire Ebolavirus and Lake Victoria Marburgvirus. Proc Natl Acad Sci U S A. 2011;108(20):8426-31.

38 Jemielity S, Wang JJ, Chan YK, Ahmed AA, Li W, Monahan S, et al. TIM-family proteins promote infection of multiple enveloped viruses through virion-associated phosphatidylserine. PLoS Pathog. 2013; 9(3): 1003232.

39 Moller-Tank S, Kondratowicz AS, Davey RA, Rennert PD, Maury W. Role of the phosphatidylserine receptor TIM-1 in enveloped-virus entry. J Virol. 2013;87(15):8327-41.

40 Morizono K, Chen IS. Role of phosphatidylserine receptors in enveloped virus infection. J Virol. 2014;88(8):4275-90.
41 Angiari S, Constantin G. Regulation of T cell trafficking by the $\mathrm{T}$ cell immunoglobulin and mucin domain 1 glycoprotein. Trends $\mathrm{Mol}$ Med. 2014;20(12):675-84.

42 Angiari S, Donnarumma T, Rossi B, Dusi S, Pietronigro E, Zenaro E, et al. TIM-1 glycoprotein binds the adhesion receptor P-selectin and mediates $\mathrm{T}$ cell trafficking during inflammation and autoimmunity. Immunity. 2014;40(4):542-53.

43 Vassena L, Giuliani E, Koppensteiner H, Bolduan S, Schindler M, Doria M. HIV-1 Nef and $\mathrm{Vpu}$ interfere with L-selectin (CD62L) cell surface expression to inhibit adhesion and signaling in infected CD4+ T lymphocytes. J Virol. 2015;89(10):5687-700.

44 Kononchik J, Ireland J, Zou Z, Segura J, Holzapfel G, Chastain A, et al. HIV-1 targets $\mathrm{L}$-selectin for adhesion and induces its shedding for viral release. Nat Commun. 2018; $9(1): 2825$.

45 Lucht A, Grunow R, Otterbein C, Möller P, Feldmann H, Becker S. Production of monoclonal antibodies and development of an antigen capture ELISA directed against the envelope glycoprotein GP of Ebola virus. Med Microbiol Immunol. 2004;193(4):181-7.

46 Lee JE, Fusco ML, Hessell AJ, Oswald WB, Burton DR, Saphire EO. Structure of the Ebola virus glycoprotein bound to an antibody from a human survivor. Nature. 2008; 454(7201):177-82.

47 Gaiha GD, Dong T, Palaniyar N, Mitchell DA, Reid KB, Clark HW. Surfactant protein A binds to HIV and inhibits direct infection of CD4+ cells, but enhances dendritic cell-mediated viral transfer. J Immunol. 2008;181(1): 601-9.

48 Edri A, Shemesh A, Iraqi M, Matalon O, Brusilovsky M, Hadad U, et al. The Ebola-glycoprotein modulates the function of natural killer cells. Front Immunol. 2018;9:1428.

49 Zhong X, Ma W, Meade CL, Tam AS, Llewellyn E, Cornell R, et al. Transient CHO expression platform for robust antibody production and its enhanced $\mathrm{N}$-glycan sialylation on therapeutic glycoproteins. Biotechnol Prog. 2019;35(1):e2724.

50 Campbell C, Stanley P. A dominant mutation to ricin resistance in Chinese hamster ovary cells induces UDP-GlcNAc:glycopeptide beta-4-N-acetylglucosaminyltransferase III activity. J Biol Chem. 1984;259(21):13370-8.

51 Stanley P, Sundaram S, Tang J, Shi S. Molecular analysis of three gain-of-function $\mathrm{CHO}$ mutants that add the bisecting GlcNAc to Nglycans. Glycobiology. 2005;15(1):43-53.

52 Harduin-Lepers A, Vallejo-Ruiz V, Krzewinski-Recchi MA, Samyn-Petit B, Julien S, Delannoy P. The human sialyltransferase family. Biochimie. 2001;83(8):727-37.

53 Hernandez Mir G, Helin J, Skarp KP, Cummings RD, Mäkitie A, Renkonen R, et al. Glycoforms of human endothelial CD34 that bind L-selectin carry sulfated sialyl Lewis $\mathrm{x}$ capped O- and N-glycans. Blood. 2009; 114(3):733-41. 
54 Sanders WJ, Katsumoto TR, Bertozzi CR, Rosen SD, Kiessling LL. L-selectin-carbohydrate interactions: relevant modifications of the Lewis x trisaccharide. Biochemistry. 1996; 35(47):14862-7.

55 Sperandio M, Gleissner CA, Ley K. Glycosylation in immune cell trafficking. Immunol Rev. 2009;230(1):97-113.

56 Tremblay MJ, Fortin JF, Cantin R. The acquisition of host-encoded proteins by nascent HIV-1. Immunol Today. 1998;19(8):346-51.

57 Segura MM, Garnier A, Di Falco MR, Whissell G, Meneses-Acosta A, Arcand N, et al. Identification of host proteins associated with retroviral vector particles by proteomic analysis of highly purified vector preparations. J Virol. 2008;82(3):1107-17.

58 Giguere JF, Paquette JS, Bounou S, Cantin R, Tremblay MJ. New insights into the functionality of a virion-anchored host cell membrane protein: CD28 versus HIV type 1. J Immunol. 2002;169:2762-71.

59 Louder MK, Sambor A, Chertova E, Hunte T, Barrett S, Ojong F, et al. HIV-1 envelope pseudotyped viral vectors and infectious molecular clones expressing the same envelope glycoprotein have a similar neutralization phenotype, but culture in peripheral blood mononuclear cells is associated with decreased neutralization sensitivity. Virology. 2005;339(2):226-38.

60 Alvarez CP, Lasala F, Carrillo J, Muñiz O, Corbí AL, Delgado R. C-type lectins DCSIGN and L-SIGN mediate cellular entry by Ebola virus in cis and in trans. J Virol. 2002; 76(13):6841-4.

61 Simmons G, Reeves JD, Grogan CC, Vandenberghe LH, Baribaud F, Whitbeck JC, et al. DC-SIGN and DC-SIGNR bind ebola glycoproteins and enhance infection of macrophages and endothelial cells. Virology. 2003; 305(1):115-23.

62 Takada A, Fujioka K, Tsuiji M, Morikawa A, Higashi N, Ebihara H, et al. Human macrophage C-type lectin specific for galactose and $\mathrm{N}$-acetylgalactosamine promotes filovirus entry. J Virol. 2004;78(6):2943-7.

63 Li M, Ablan SD, Miao C, Zheng YM, Fuller MS, Rennert PD, et al. TIM-family proteins inhibit HIV-1 release. Proc Natl Acad Sci U S A. 2014;111(35):E3699-707.

64 Lee HH, Meyer EH, Goya S, Pichavant M, Kim HY, Bu X, et al. Apoptotic cells activate NKT cells through T cell Ig-like mucin-like-1 resulting in airway hyperreactivity. J Immunol. 2010;185(9):5225-35.

65 Wolf Y, Anderson AC, Kuchroo VK. TIM3 comes of age as an inhibitory receptor. Nat Rev Immunol. 2020;20(3):173-85.

66 Younan P, Iampietro M, Nishida A, Ramanathan P, Santos RI, Dutta M, et al. Ebola virus binding to Tim-1 on T lymphocytes induces a cytokine storm. mBio. 2017;8(5):e00845-17.
67 Ivetic A, Hoskins Green HL, Hart SJ, L-selectin . L-selectin: a major regulator of leukocyte adhesion, migration and signaling. Front Immunol. 2019;10:1068.

68 Nishimura Y, Shimojima M, Tano Y, Miyamura T, Wakita T, Shimizu H. Human Pselectin glycoprotein ligand- 1 is a functional receptor for enterovirus 71. Nat Med. 2009; 15(7):794-7.

69 Avril T, Attrill H, Zhang J, Raper A, Crocker PR. Negative regulation of leucocyte functions by CD33-related siglecs. Biochem Soc Trans. 2006;34(6): 1024-7.

70 Lubbers J, Rodriguez E, van Kooyk Y. Modulation of immune tolerance via siglec-sialic acid interactions. Frontiers Immunol. 2018;9.

71 Stanczak MA, Siddiqui SS, Trefny MP, Thommen DS, Boligan KF, von Gunten S, et al. Selfassociated molecular patterns mediate cancer immune evasion by engaging Siglecs on $\mathrm{T}$ cells. J Clin Invest. 2018;128(11):4912-23.

72 Cagnoni AJ, Pérez Sáez JM, Rabinovich GA, Mariño KV. Turning-off signaling by siglecs, selectins, and galectins: chemical inhibition of glycan-dependent interactions in cancer. Front Oncol. 2016;6:109.

73 Jandus C, Boligan KF, Chijioke O, Liu H, Dahlhaus $M$, Démoulins $T$, et al. Interactions between Siglec-7/9 receptors and ligands influence NK cell-dependent tumor immunosurveillance. J Clin Invest. 2014;124(4):181020.

74 Ray RB, Basu A, Steele R, Beyene A, McHowat J, Meyer K, et al. Ebola virus glycoproteinmediated anoikis of primary human cardiac microvascular endothelial cells. Virology. 2004;321(2):181-8.

75 Yang ZY, Duckers HJ, Sullivan NJ, Sanchez A, Nabel EG, Nabel GJ. Identification of the Ebola virus glycoprotein as the main viral determinant of vascular cell cytotoxicity and injury. Nat Med. 2000;6(8):886-9.

76 Alazard-Dany N, Volchkova V, Reynard O, Carbonnelle C, Dolnik O, Ottmann M, et al. Ebola virus glycoprotein GP is not cytotoxic when expressed constitutively at a moderate level. J Gen Virol. 2006;87(Pt 5):1247-57.

77 Lanitis E, Dangaj D, Irving M, Coukos G. Mechanisms regulating T-cell infiltration and activity in solid tumors. Ann Oncol. 2017; 28(Suppl 12):xii18-32.

78 Gajewski TF, Schreiber H, Fu YX. Innate and adaptive immune cells in the tumor microenvironment. Nat Immunol. 2013;14(10):101422.

79 Patel M, Yanagishita M, Roderiquez G, BouHabib DC, Oravecz T, Hascall VC, et al. Cellsurface heparan sulfate proteoglycan mediates HIV-1 infection of T-cell lines. AIDS Res Hum Retroviruses. 1993;9(2):167-74.
80 Xu Y, Martinez P, Séron K, Luo G, Allain F, Dubuisson J, et al. Characterization of hepatitis $C$ virus interaction with heparan sulfate proteoglycans. J Virol. 2015;89(7):3846-58.

81 Kalia M, Chandra V, Rahman SA, Sehgal D, Jameel S. Heparan sulfate proteoglycans are required for cellular binding of the hepatitis $\mathrm{E}$ virus ORF2 capsid protein and for viral infection. J Virol. 2009;83(24):12714-24.

82 Salvador B, Sexton NR, Carrion R Jr, Nunneley J, Patterson JL, Steffen I, et al. Filoviruses utilize glycosaminoglycans for their attachment to target cells. J Virol. 2013;87(6): 3295-304.

83 O'Hearn A, Wang M, Cheng H, Lear-Rooney $\mathrm{CM}$, Koning K, Rumschlag-Booms E, et al. Role of EXT1 and glycosaminoglycans in the early stage of filovirus entry. J Virol. 2015; 89(10):5441-9.

84 Lin CL, Chung CS, Heine HG, Chang W. Vaccinia virus envelope $\mathrm{H} 3 \mathrm{~L}$ protein binds to cell surface heparan sulfate and is important for intracellular mature virion morphogenesis and virus infection in vitro and in vivo. J Virol. 2000;74(7):3353-65.

85 Surviladze Z, Sterkand RT, Ozbun MA. Interaction of human papillomavirus type 16 particles with heparan sulfate and syndecan-1 molecules in the keratinocyte extracellular matrix plays an active role in infection. J Gen Virol. 2015;96(8):2232-41.

86 Whitley R, Kimberlin DW, Prober CG. Pathogenesis and disease. In: Arvin A, Campadelli-Fiume G, Mocarski E, Moore PS, Roizman B, Whitley R, et al., editors. Human Herpesviruses: Biology, Therapy, and Immunoprophylaxis. Cambridge, UK: Cambridge University Press; 2007.

87 Shukla D, Liu J, Blaiklock P, Shworak NW, Bai $\mathrm{X}$, Esko JD, et al. A novel role for 3-O-sulfated heparan sulfate in herpes simplex virus 1 entry. Cell. 1999;99(1):13-22.

88 Tamhankar M, Gerhardt DM, Bennett RS, Murphy N, Jahrling PB, Patterson JL. Heparan sulfate is an important mediator of Ebola virus infection in polarized epithelial cells. Virol J. 2018;15(1): 135 .

89 Falasca L, Agrati C, Petrosillo N, Di Caro A, Capobianchi MR, Ippolito G, et al. Molecular mechanisms of Ebola virus pathogenesis: focus on cell death. Cell Death Differ. 2015; 22(8):1250-9.

90 Noyori O, Nakayama E, Maruyama J, Yoshida R, Takada A. Suppression of Fas-mediated apoptosis via steric shielding by filovirus glycoproteins. Biochem Biophys Res Commun. 2013;441(4):994-8

91 Warfield KL, Perkins JG, Swenson DL, Deal EM, Bosio CM, Aman MJ, et al. Role of natural killer cells in innate protection against lethal ebola virus infection. J Exp Med. 2004; 200(2):169-79. 